\title{
Refill Friction Stir Spot Welding Al Alloy to Copper via Pure Metallurgical Joining Mechanism
}

\author{
Zhikang Shen ${ }^{1,2^{*}}$, Yuquan Ding ${ }^{2}$, Wei Guo ${ }^{1}$, Wentao Hou ${ }^{2}$, Xiaochao Liu ${ }^{1 *}$, Haiyan Chen ${ }^{1}$, Fenjun Liu ${ }^{3}$,
} Wenya $\mathrm{Li}^{1}$ and Adrian Gerlich ${ }^{1}$

\begin{abstract}
The current investigation of refill friction stir spot welding (refill FSSW) Al alloy to copper primarily involved plunging the tool into bottom copper sheet to achieve both metallurgical and mechanical interfacial bonding. Compared to conventional FSSW and pinless FSSW, weld strength can be significantly improved by using this method. Nevertheless, tool wear is a critical issue during refill FSSW. In this study, defect-free Al/copper dissimilar welds were successfully fabricated using refill FSSW by only plunging the tool into top Al alloy sheet. Overall, two types of continuous and ultra-thin intermetallic compounds (IMCs) layers were identified at the whole Al/copper interface. Also, strong evidence of melting and resolidification was observed in the localized region. The peak temperature obtained at the center of Al/copper interface was $591^{\circ} \mathrm{C}$, and the heating rate reached up to $916^{\circ} \mathrm{C} / \mathrm{s}$ during the sleeve penetration phase. A softened weld region was produced via refill FSSW process, the hardness profile exhibited a W-shaped appearance along middle thickness of top Al alloy. The weld lap shear load was insensitive to the welding condition, whose scatter was rather small. The fracture path exclusively propagated along the IMCs layer of $\mathrm{Cu}_{9} \mathrm{Al}_{4}$ under the external lap shear loadings, both $\mathrm{CuAl}_{2}$ and $\mathrm{Cu}_{9} \mathrm{Al}_{4}$ were detected on the fractured surface on the copper side. This research indicated that acceptable weld strength can be achieved via pure metallurgical joining mechanism, which has significant potential for the industrial applications.
\end{abstract}

Keywords: Refill friction stir spot welding, Al alloy, Copper, Interfacial microstructure, Mechanical properties

\section{Introduction}

In order to obtain technical and economic advantages, joining of dissimilar materials is gaining wide popularity in the industries [1-4]. For instance, $\mathrm{Al}$ and copper alloys are useful for electrical and thermal applications, since they have excellent electrical and thermal conductivities [5]. However, it is a critical issue to fusion join $\mathrm{Al}$ alloy to copper since they can produce thick and continuous intermetallic compounds (IMCs) [6, 7]. Mechanical joining approaches such as self-piercing riveting can

\footnotetext{
*Correspondence: z45shen@uwaterloo.ca; xcliu1990@seu.edu.cn

${ }^{1}$ School of Materials Science and Engineering, Northwestern

Polytechnical University, Xi'an 710072, China

Full list of author information is available at the end of the article
}

result in poor work environment, low work efficiency and weight increment of structures [8]. It is inspiring that solid phase joining technique such as explosive welding [9], ultrasonic welding [10], friction welding [11], friction stir welding (FSW) [12-16], and conventional friction stir spot welding (FSSW) are feasible approaches to join dissimilar metals [17], since they could avoid solidification, liquation cracking and porosity which are common occurred during fusion welding.

Compared to conventional and pinless FSSW, mechanical performance of refill FSSWed joint can be dramatically improved by increasing the weld effective bonded volume and integrity [18]. As presented in Figure 1, a tool comprises a clamping ring, a sleeve and a pin is applied during refill FSSW, the weld is fabricated by plasticizing, 


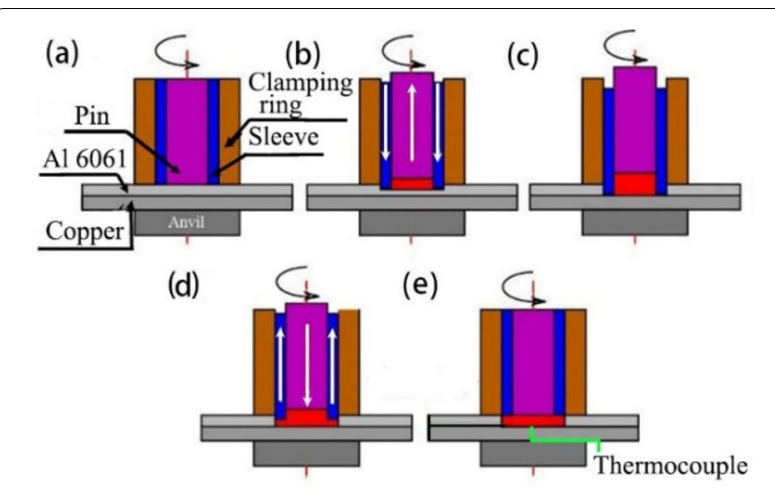

Figure 1 Refill FSSW process: (a) preheating before penetration, (b) sleeve penetration, (c) stirring after penetration, (d) sleeve retraction, and (e) flatten weld surface after retraction

and displacing the material in a process similar to back extrusion and forging, whose detailed joining processes were provided elsewhere [18-21]. Role of the stational clamping ring is to steadily hold the workpieces, prevent the coupons from separating, and avoid overflow the softened material from the stirring area [20]. The sleeve and pin can rotate in the same direction by using the same motor, and move up and down independently by using two actuators [19]. Refill FSSW provides a number of benefits compared to fusion welding and mechanical joining methods, since it can minimize IMCs layer thickness by suppressing the temperature rise, providing many virtues for joining lightweight materials and dissimilar combinations [22-28].

Currently, joining $\mathrm{Al}$ alloys to copper by FSW and conventional FSSW has been extensively studied, in which the bonding mechanism includes both metallurgical bonding and mechanical interlocking by plunging the tool pin into the bottom hard copper materials $[26,29,30]$. Compared to that in FSW, tool wear could be much more excessive in FSSW, because severe tool wear primarily takes place during the plunging phase [17]. The three-components tool utilized in refill FSSW was always made of tool steel due to that the tool design was very complicated. Hence, it can be expected that the tool threads could be severely worn off, if it was plunged into the copper sheet material to obtain the mechanical interlocking joining mechanism by displacing the bottom copper material into to $\mathrm{Al}$ alloy [30-32]. Under the circumstances, IMCs layer formation is indispensable to achieve metallurgical bonding at the interface. Nevertheless, the weld strength will be seriously deteriorated once the IMCs layer exceeds a critical thickness. Previous literatures revealed that tool sleeve penetration depth is the decisive factor determines the interfacial reaction, IMCs layer growth and thus mechanical properties $[24,26,27$,

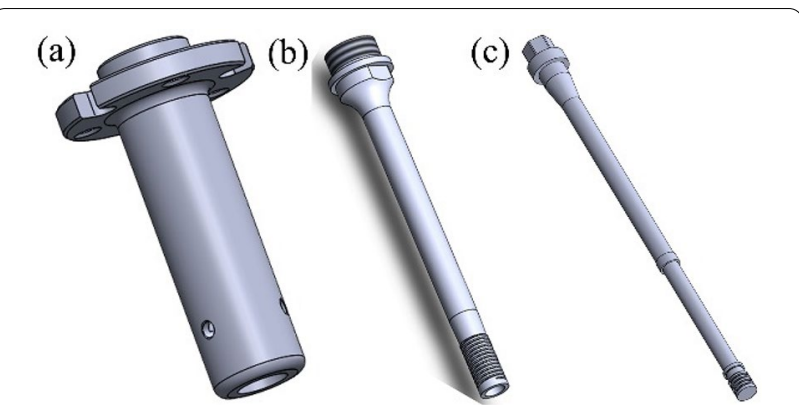

Figure 2 Geometrical feature of (a) clamping ring, (b) sleeve and (c) pin

31]. Therefore, purpose of the present investigation is to clarify the function of tool sleeve penetration depth on interfacial reaction and mechanical performance of refill friction stir spot welded $\mathrm{Al} /$ copper welds, in terms of interfacial microstructure, hardness profile, weld lap shear load and failure mechanism based on the experimental examination.

\section{Experimental Procedure}

The as-received materials utilized in this investigation were $2.0 \mathrm{~mm}$ thick $\mathrm{Al} 6061-\mathrm{T} 4$ and $0.5 \mathrm{~mm}$ thick commercial pure copper, respectively. Chemical component of $\mathrm{Al} 6061-\mathrm{T} 4$ is $0.04-0.35 \mathrm{Cr}, 0.15-0.4 \mathrm{Cu}, 0.8-1.2 \mathrm{Mg}$, $0.4-0.8 \mathrm{Si},<0.7 \mathrm{Fe},<0.15 \mathrm{Ti},<0.25 \mathrm{Zn}, \mathrm{Al}$ bal. (wt-\%). The welding operation was conducted using a Harms \& Wende RPS100 refill friction stir spot welding machine provided by Coldwater Machine Company. The threaded tool was made of $\mathrm{H} 13$ tool steel, function of the threads machined on the sleeve surface was to enhance the material flow performance and facilitate chip removal. Geometries of the clamping ring, sleeve and pin were schematically shown Figure 2, whose diameters were $14.5,9.0$ and $6.4 \mathrm{~mm}$, respectively [21].

In order to minimize tool wear, $\mathrm{Al} 6061$ sheet material was set as the top coupon (Figure 1), and the welds were manufactured in the center of the $25 \mathrm{~mm} \times 25 \mathrm{~mm}$ overlapped area of two $25 \mathrm{~mm} \times 100 \mathrm{~mm}$ overlapped coupons. Industrial alcohol was used to clean impurities on the coupon surfaces such as dirt and oil before welding operation. Then, the $\mathrm{Al} /$ copper dissimilar spot welds were manufactured using a rotational rate of $1800 \mathrm{r} / \mathrm{min}$, a surface dwell time of $0.5 \mathrm{~s}$ (before plunging), a plunging time of $0.5 \mathrm{~s}$, a dwell time of $3 \mathrm{~s}$, a retreating time of $0.5 \mathrm{~s}$ and a surface dwell time of $0.5 \mathrm{~s}$ (after retreating). Role of surface dwell time before the plunging and after retreating was to preheat and platen the materials to be joined [21]. The above-mentioned welding variants remain constant, while the tool sleeve penetration depth 
varies from $1.2 \mathrm{~mm}$ to $1.8 \mathrm{~mm}$. In order to prevent steel sleeve is plugged into bottom of the copper sheet material and thus damaging the thermocouple, one $0.1 \mathrm{~mm}$ deep groove and hole $(0.1 \mathrm{~mm}$ diameter $)$ were machined on the bottom copper sheet, and a 0.1 diameter K-type thermocouple was inserted into the $\mathrm{Al} /$ copper interface center to record the temperatures (see Figure 1e).

After joining process, the weld was cut along weld center using wire-electrode cutting, and then prepared using standard metallographic techniques such as grinding and polishing. Afterwards, weld microstructures were examined by using an OLYMPUS NTB 3558 optical microscope after the sample was chemically etched by Keller's reagent for $15 \mathrm{~s}$. The Al/copper weld interfacial microstructure and the fractured surfaces morphology were examined using a JEOL JSM-6460 scanning electron microscope. All of the chemical compositions measured by energy dispersive X-ray (EDX) spectroscopy were reported as wt\%. The weld lap shear load was performed on a CHANGCHUN CSS-44100 electronic universal testing machine provided by China Machine Testing Equipment Co. LTD, using a constant cross head speed of $10 \mathrm{~mm} / \mathrm{min}$, which was reported as the average of three individual testing samples. The hardness measurement was conducted along mid-thickness of to $\mathrm{Al}$ alloy using a LECO AMH 43 hardness tester produced by Leco Corporation, with a load of $5 \mathrm{gf}$ and a dwell time of 10 s. X-ray diffraction (XRD) was used to identify the IMCs phases at the fractured surfaces on the copper side.

\section{Results and Discussion}

\subsection{Interfacial Bonding}

Cross sectional view of the weld fabricated utilizing a sleeve penetration depth of $1.8 \mathrm{~mm}$ was selected to investigate the weld macrostructure and interfacial microstructure (see Figure 3), where the sleeve plunging and retreating path was labeled by blue dotted lines. The weld top surface was uniform to that of the $\mathrm{Al}$ alloy coupon, suggesting no softened material was squeezed out of the stirring area during the entire joining process. The $\mathrm{Al} /$ copper interface was rather flat, and no micro-level plastic deformation or hooking feature can be observed due to that the tool sleeve did not penetrate into the bottom copper sheet material. Also, macroscopic defects such as lack of or no mixing, incomplete refill or bonding

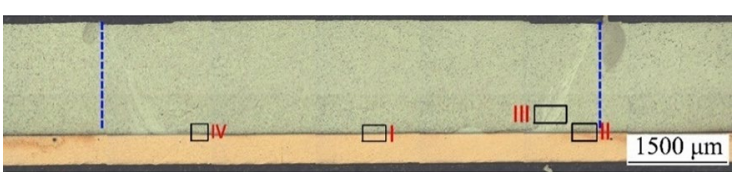

Figure 3 Cross sectional view of the weld manufactured using a 1.8 $\mathrm{mm}$ penetration depth ligament were not formed in the weld, since a relatively longer dwell time was applied after the plunging phase. It is worth noting that previous studies indicated that the top sheet material microstructure did not influence the weld performance, since the weld failure always propagated along the weld interface [24-27], and the refill FSSWed Al 6061 microstructures have been extensively investigated [33]. Thus, the present investigation primarily focused on the $\mathrm{Al} /$ copper interfacial microstructure.

With the purpose of clarifying the interfacial microstructure and material flow pattern at the $\mathrm{Al} /$ copper faying interface, enlarged views in the rectangles I-IV in Figure 3 were presented in Figures 4, 5, 6, respectively. As shown in Figures 4 and 5, intimate bonding was achieved, and no microdefects such as voids, poles or cracking can be observed at the entire $\mathrm{Al} /$ copper interface. As presented in Figure 4 and Table 1, two different types of continuous IMCs layers were produced at the weld center. The IMCs layer adjacent to top $\mathrm{Al}$ sheet material was approximately $1.5 \mu \mathrm{m}$ thick, where the average chemical
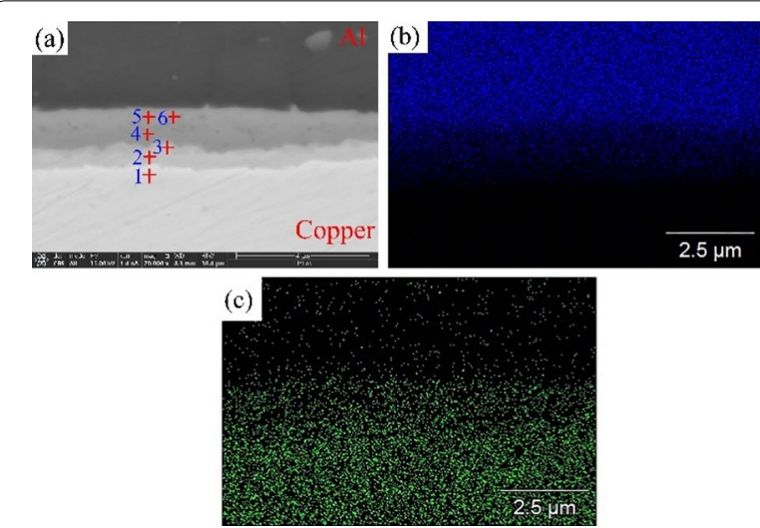

Figure 4 (a) SEM image of region I in Figure 3, and element maps for (b) $\mathrm{Al}$ and (c) $\mathrm{Cu}$

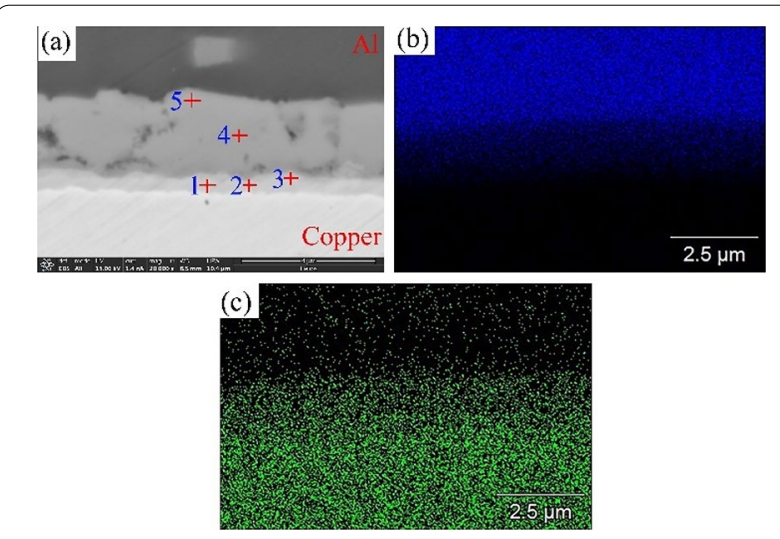

Figure 5 (a) SEM image of region II in Figure 3, and element maps for (b) Al and (c) Cu 

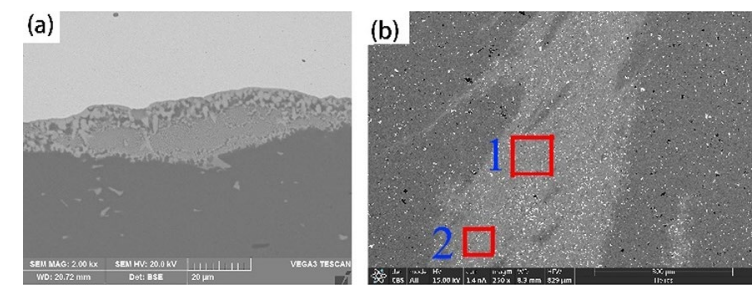

Figure 6 SEM image of regions (a) IV and (b) III in Figure 3

Table 1 EDX quantification results (wt\%) indicated in Figure 4

\begin{tabular}{llll}
\hline Location & Al & Cu & Total \\
\hline 1 & 2.8 & 97.2 & 100.0 \\
2 & 22.4 & 77.6 & 100.0 \\
3 & 33.0 & 67.0 & 100.0 \\
4 & 49.0 & 51.0 & 100.0 \\
5 & 63.5 & 36.5 & 100.0 \\
6 & 56.9 & 43.1 & 100.0 \\
\hline
\end{tabular}

Table 2 EDX quantification results (wt\%) indicated in Figure 5

\begin{tabular}{llll}
\hline Location & Al & Cu & Total \\
\hline 1 & 19.7 & 80.3 & 100.0 \\
2 & 19.9 & 80.1 & 100.0 \\
3 & 32.6 & 67.4 & 100.0 \\
4 & 44.9 & 55.1 & 100.0 \\
5 & 53.9 & 46.1 & 100.0 \\
\hline
\end{tabular}

component was $56.5 \% \mathrm{Al}$ and $43.5 \% \mathrm{Cu}$ (locations 4,5 and 6), which was consistent with that of $\mathrm{CuAl}_{2}$. While the thickness of the IMCs layer attached to the bottom copper sheet was approximate $0.5 \mu \mathrm{m}$ thick, where the average chemical component was $27.7 \% \mathrm{Al}$ and $72.3 \% \mathrm{Cu}$ (locations 2 and 3), consistent with that of $\mathrm{Cu}_{9} \mathrm{Al}_{4}$ according to $\mathrm{Al}-\mathrm{Cu}$ phase diagram.

As shown in Figure 5, the IMCs layer was slightly thicker at the weld edge (approximate $3.0 \mu \mathrm{m}$ ) compared to that in the weld center, where more frictional heat can be generated due to the higher linear velocity of the rotating sleeve. The IMCs layer adjacent to the top Al 6061 sheet material was approximately $2.7 \mu \mathrm{m}$ thick, where the average chemical component was $43.8 \% \mathrm{Al}$ and $56.2 \% \mathrm{Cu}$ (see Table 2, locations 3, 4 and 5), consistent with that of $\mathrm{CuAl}_{2}$. It is interesting to be noted that the IMCs layer adjacent to the bottom copper sheet was extremely thin (approximate $0.3 \mu \mathrm{m}$ ) where the heat can be readily dissipated to the surroundings, and the

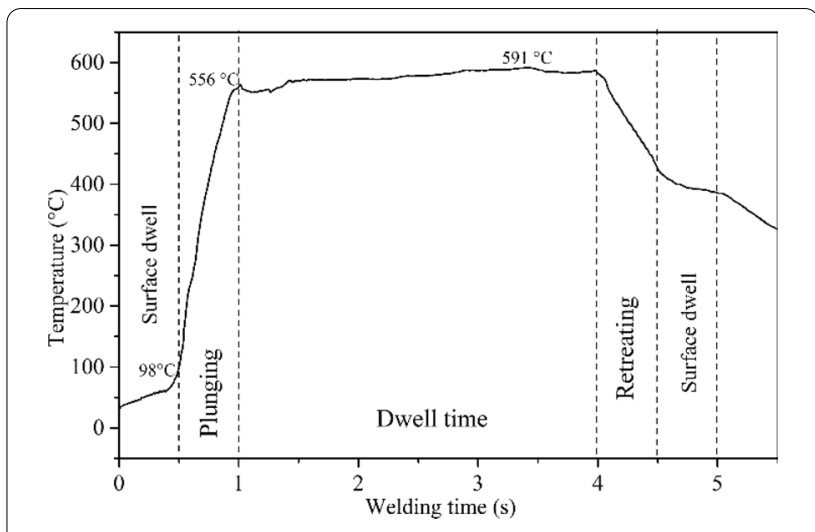

Figure 7 Thermal cycle measured at the weld interface center

Table 3 EDX quantification results (wt\%) indicated in Figure 6b

\begin{tabular}{lllll}
\hline Location & $\mathbf{M g}$ & $\mathbf{A l}$ & $\mathbf{C u}$ & Table \\
\hline 1 & 0.6 & 94.3 & 5.1 & 100.0 \\
2 & 0.6 & 93.8 & 5.6 & 100.0 \\
\hline
\end{tabular}

average chemical component was $19.8 \% \mathrm{Al}$ and $80.2 \% \mathrm{Cu}$ (see Table 2, locations 1 and 2) and consistent with that of $\mathrm{Cu}_{9} \mathrm{Al}_{4}$. As shown in Figures 4b, 4c and Figures 5b, 5c, interdiffusion can be clearly identified between the top IMC layers and $\mathrm{Al}$ alloy stir zone (SZ), since fine grain size produced by dynamic recrystallization is beneficial to the mutual diffusion. A maximum temperature of 591 ${ }^{\circ} \mathrm{C}$ (with a temperature rising rate of $916{ }^{\circ} \mathrm{C} / \mathrm{s}$ during the plunging phase) was obtained at the weld center (see Figure 7), which readily explained the interfacial microstructure formation. Encouragingly, the IMCs thickness was much thinner than those formed in fusion welding, and thus beneficial to the weld strength.

As shown in Figure 6a, it is interesting to be noted that evidence of resolidification and relatively thick IMCs layer can be observed in the localized region at the $\mathrm{Al} /$ copper interface, which can be attributed to high temperature exposure and mutual diffusion promoted by the refill FSSW process [26]. Furthermore, through-interface material flow pattern can be clearly identified around the weld edge (see Figures 3 and $6 \mathrm{~b}$ ), a fraction of $\mathrm{Cu}$ content was displaced upwards into the top $\mathrm{Al}$ sheet (see Table 3). Such a material flow pattern has been reported during refill friction stir spot welded $\mathrm{Mg} /$ steel [31], $\mathrm{Al} /$ steel and $\mathrm{Al} / \mathrm{Mg}$ dissimilar welds $[25,28]$. This material flow pattern has been identified to be formed during the sleeve plunging phase and further propagated to the weld top surface during the sleeve retreating phase [28]. 


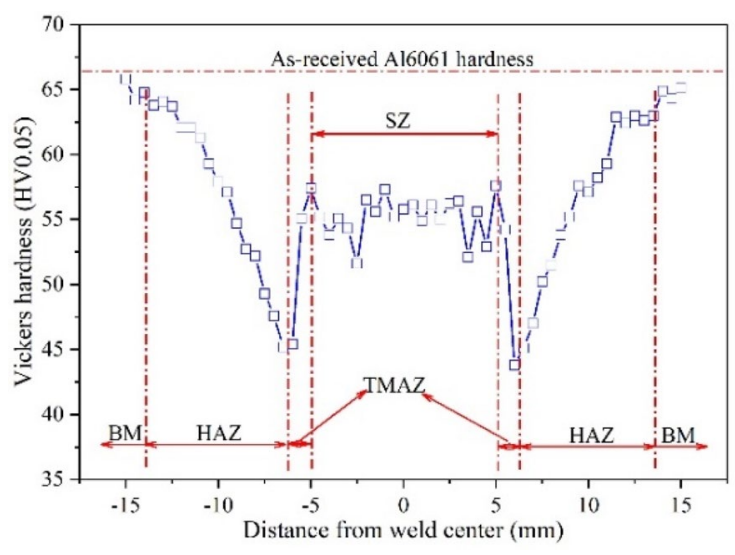

Figure 8 Hardness profile along mid-thickness of Al 6061 sheet

\subsection{Mechanical Properties}

\subsubsection{Hardness}

Hardness profile conducted along middle thickness of the top $\mathrm{Al} 6061$ sheet of the weld fabricated under a 1.8
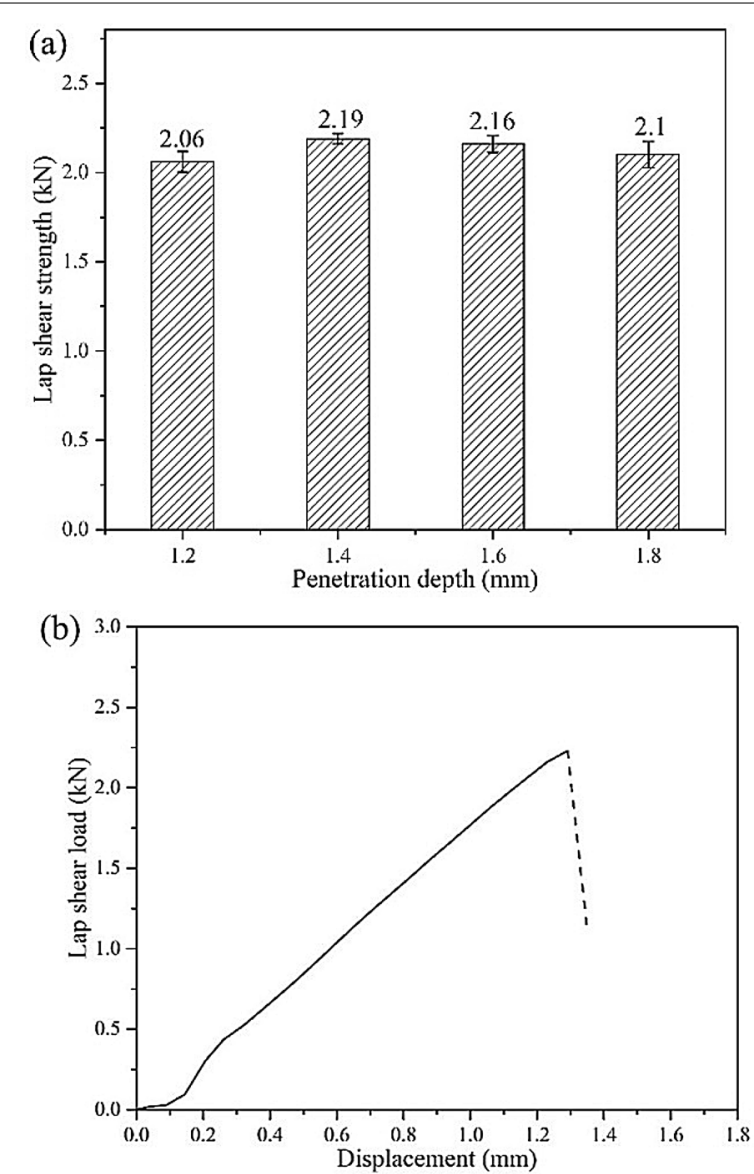

Figure 9 (a) relation between sleeve penetration depth and weld lap shear strength, (b) typical lap shear load/displacement curve of Al/copper weld

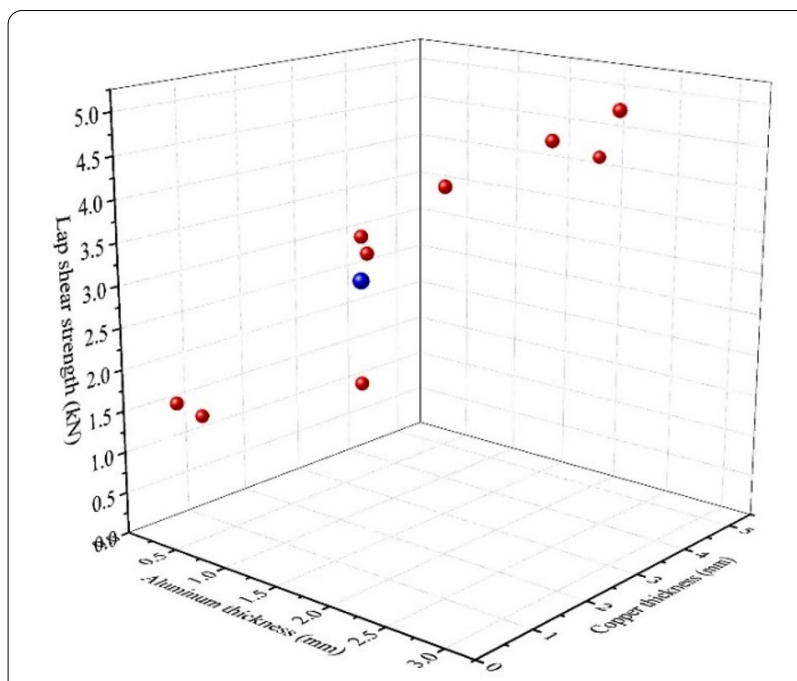

Figure 10 Summary of published workpiece thickness versus Al/ copper spot welds lap shear strength [35-43]

mm penetration depth was shown in Figure 8. It can be observed that a softened welded zone was produced by the combination of frictional heat and plastic deformation derived from refill FSSW process, which is consistent with the previous research [33]. Overall, the hardness profile presented a W-shaped appearance since Al 6061 was a precipitation-hardened alloy, whose hardness was
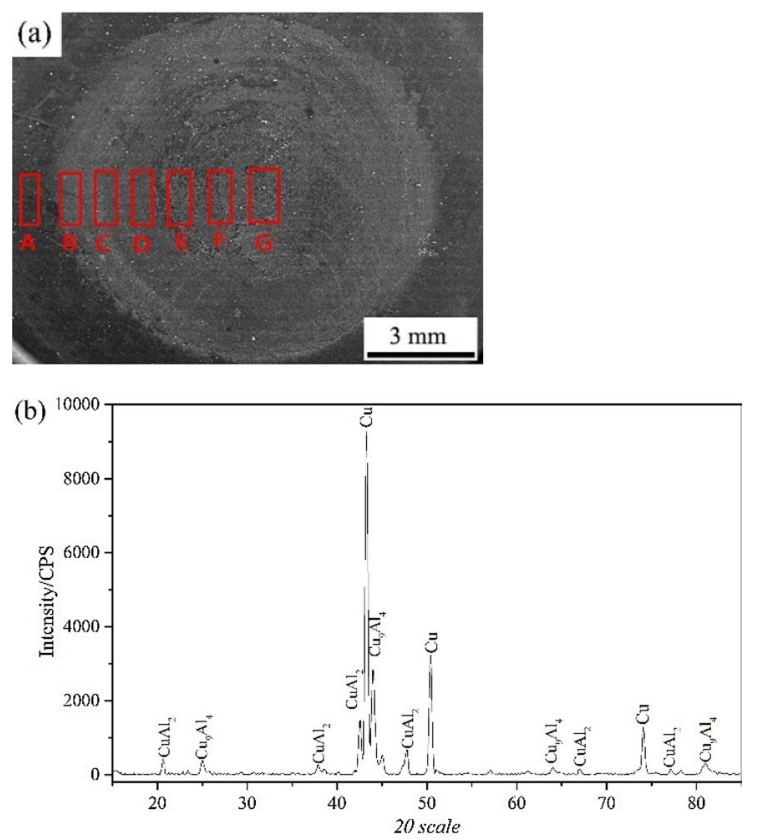

Figure 11 (a) Interfacial fractured surface on the cupper side of the weld fabricated using a sleeve penetration depth of $1.8 \mathrm{~mm},(\mathbf{b})$ XRD patterns obtained from the fracture surfaces 
Table 4 EDX quantification results (wt\%) indicated in Figure 11a

\begin{tabular}{llllllll}
\hline Location & A & B & C & D & E & F \\
\hline Al & - & 22.9 & 31.8 & 29.2 & 19.4 & 53.2 & 34.8 \\
$\mathrm{Cu}$ & 100.0 & 77.1 & 68.2 & 70.8 & 80.6 & 46.8 & 65.2 \\
\hline
\end{tabular}

primarily governed by the state and distribution of precipitates $\left(\mathrm{Mg}_{2} \mathrm{Si}\right)$ and scarcely affected by grain size [21]. The minimum hardness was measured at the junction of thermo-mechanically affected zone (TMAZ) and heat affected zone (HAZ), where the material experienced the highest temperatures besides SZ, resulting in coarsening or dissolution of the precipitate particles. However, the hardness gradually increased in the TMAZ and reached a plateau in the $\mathrm{SZ}$ due to reprecipitation of $\mathrm{Mg}_{2} \mathrm{Si}$ during the following natural aging [34].

\subsubsection{Lap Shear Strength}

Relationship between tool sleeve penetration depth and weld lap shear load was presented in Figure 9a. Overall, the weld lap shear load was insensitive to the welding condition, because the frictional heat can be immediately dissipated to the steel anvil through the bottom copper sheet material, although higher penetration depth/ rate could generate more heat. The weld lap shear load slightly increased to a maximum value of $2.19 \mathrm{kN}$ when the penetration improved from $1.2 \mathrm{~mm}$ to $1.4 \mathrm{~mm}$, which further slightly reduced to $2.10 \mathrm{kN}$ when the sleeve penetration depth improved from 1.4 to $1.8 \mathrm{~mm}$. As indicated in Figure 10, compared to the lap shear load of FSSWed $\mathrm{Al} /$ copper dissimilar welds derived from both metallurgical bonding and mechanical inter-locking mechanisms, it can be concluded that acceptable weld strength can be achieved via pure metallurgical joining mechanism. Figure $9 \mathrm{~b}$ shows a typical lap shear load/displacement curve of the weld fabricated using a penetration depth of 1.8 $\mathrm{mm}$, it is clearly that the weld failed in a brittle manner, because the fracture exclusively propagated through the IMCs layer (see Figure 11).

\subsubsection{Failure Mode}

Figure 11a presents a typical fractured surface of the $\mathrm{Al}$ / copper weld on the copper side of a fractured weld fabricated using a sleeve penetration depth of $1.8 \mathrm{~mm}$. It should be noted that only interfacial failure mode was observed when the welds were evaluated under external lap shear loadings. The fracture area was consistent with the diameter of the rotating sleeve, which was really flat and no macroscopic or microscopic deformation can be observed. The fracture initiated at the weld edge $\left(\mathrm{Cu}_{9} \mathrm{Al}_{4}\right.$ layer $)$ and then propagated towards the weld center and along the weld edge. The chemical component distribution and XRD patterns obtained from the fractured surfaces were shown in Table 4 and Figure 11b, respectively. The fracture exclusively propagated long the $\mathrm{Cu}_{9} \mathrm{Al}_{4}$ IMCs layer, both $\mathrm{CuAl}_{2}$ and $\mathrm{Cu}_{9} \mathrm{Al}_{4}$ were detected on the fractured surfaces.

\section{Conclusions}

In this investigation, interfacial microstructure and mechanical performance of $\mathrm{Al} /$ copper dissimilar refill friction stir spot welds were systematically evaluated in terms of interfacial microstructure, hardness profile, lap shear load and failure mechanism. The following conclusions can be drawn based on the experimental observations:

(1) Defect-free $\mathrm{Al} /$ copper welds were manufactured by refill FSSW using a standard sleeve tool under all welding conditions applied in the present study. Two different types of thin and continuous IMCs layers were produced at the $\mathrm{Al} /$ copper interface, which was thicker at the weld edge and thin at the weld interface center. Evidence of resolidification was identified at the localized region and upwards material flow pattern was observed around the weld edge.

(2) A softened welded zone was produced in the top Al 6061 sheet material, and the hardness profile presented a W-shaped appearance. The minimum hardness was identified at the junction of TMAZ and HAZ.

(3) The weld lap shear load was relatively repeatable and insensitive to the welding condition. Acceptable weld strength can be achieved through pure metallurgical joining mechanism. The fracture exclusively propagated along the IMCs layer of $\mathrm{Cu}_{9} \mathrm{~A}_{14}$ under the external lap shear loads, both $\mathrm{CuAl}_{2}$ and $\mathrm{Cu}_{9} \mathrm{Al}_{4}$ were detected on the fractured surfaces.

\section{Acknowledgements}

The authors sincerely thanks Chris Gobbi and Michael Booth for their assistance with tooling fabrication.

\section{Authors' Contributions}

$\mathrm{ZS}$ was in charge of part of trial and wrote the manuscript; $Y D$ proposed useful suggestions for the analysis; WG, WH, XL, HC and FL did the rest of trial; $W L$ made some correction of the manuscript. AG guided the writing and trial. All authors read and approved the final manuscript. 


\begin{abstract}
Authors' Information
Zhikang Shen, born in 1983, is currently an associate professor in Northwestern Polytechnical University, China. He received his PhD degree from Tianjin University, China, in 2015. He received his master degree from Lanzhou University of Science and Technology, China, in 2011. His current research focuses on friction stir spot welding.
\end{abstract}

Yuquan Ding, born in 1965, is currently a materials characterization specialist in University of Waterloo, Canada. He received his master and PhD degree from Zhejiang University, China, in 1985 and 1988, respectively.

Wei Guo, born in 1985, is currently a postdoc at Northwestern Polytechnical University, China. He received his PhD degree from Harbin Institute of Technology, China, in 2018. He received his master degree from Northeastern University, China, in 2014. His current research focuses on brazing.

Wentao Hou, born in 1986, is currently a PhD candidate in University of Waterloo, Canada.

Xiaochao Liu, born in 1990, is currently an associate professor at Northwestern Polytechnical University, China. He received his PhD degree from Osaka University, Japan, in 2018. He received his master degree from Shandong University, China, in 2015. His current research focuses on friction stir welding of highsoftening temperature materials.

Haiyan Chen, born in 1984, is currently an associate professor at Northwestern Polytechnical University, China. He received his PhD degree from Harbin Institute of Technology, China, in 2013. He received his master degree from University of Chinese Academy of Sciences, China, in 2010. His current researches focus on friction stir welding and brazing.

Fenjun Liu, born in 1982, is currently an associate professor in Yulin University, China. He received his PhD degree from Northwestern Polytechnical University, China, in 2018. He received his master degree from Taiyuan University of Technology, China, in 2009. His current research focuses on high-speed friction stir welding.

Wenya Li, born in 1976, is currently a professor at Northwestern Polytechnical University, China. He received his Master degree and PhD degree from Xi'an Jiaotong University, China, in 2001 and 2005, respectively. His current researches focus on friction stir welding and cold spraying.

Adrian Gerlich, born in 1979, is currently an associate professor in University of Waterloo, Canada. He received his Bachelor degree and PhD degree from University of Toronto, Canada, in 2003 and 2007, respectively. His current researches focus on friction stir welding and additive manufacturing.

\section{Funding}

Supported by National Natural Science Foundation of China (Grant Nos. 51975479, 51905437), Fundamental Research Funds for the Central Universities (Grant No. 3102019QD0404), Science and Technology Bureau of Yulin (Grant No. 2019-86-1), and High-Level Talent Project of Yulin University, China (Grant No. 20GK06).

\section{Competing Interests}

The authors declare no competing financial interests.

\section{Author Details}

'School of Materials Science and Engineering, Northwestern Polytechnical University, Xi'an 710072, China. ${ }^{2}$ Centre for Advance Materials Joining, University of Waterloo, Waterloo N2L 3G1, Canada. ${ }^{3}$ College of Energy Engineering, Yulin University, Yulin 719000, China.

Received: 10 March 2020 Revised: 29 December 2020 Accepted: 5 August 2021

Published online: 19 August 2021

\section{References}

[1] H Bian, X Song, S Hu, et al. Microstructure evolution and mechanical properties of titanium/alumina brazed joints for medical implants. Metals, 2019, 9(6): 644

[2] L Zhou, M Yu, B Liu, et al. Microstructure and mechanical properties of Al/steel dissimilar welds fabricated by friction surfacing assisted friction stir lap welding. Journal of Materials Research and Technology, 2020, 9(1): 212-221.

[3] $M X u, B$ Liu, Y Zhao, et al. Direct joining of thermoplastic ABS to aluminium alloy 6061-T6 using friction lap welding. Science and Technology of Welding and Joining, 2019, https://doi.org/10.1080/13621718.2020. 1719304.

[4] Z Shen, H Sui, V Kerr, et al. Effect of heat treatment on the interfacial bonding between $\mathrm{SiC}$ coating and alumina plate. Surface Engineering, 2020, 36(4): 397-404.

[5] K P Mehta, V J Badheka. A review on dissimilar friction stir welding of copper to aluminum: process, properties, and variants. Materials and Manufacturing Processes, 2016, 31(3): 233-254.

[6] H Sui, N Huda, Z Shen, et al. Al-NiO energetic composites as heat source for joining silicon wafer. Journal of Materials Processing Technology, 2019, 279: 116572.

[7] R Sun, L Li, Y Zhu, et al. Microstructure, residual stress and tensile properties control of wire-arc additive manufactured 2319 aluminum alloy with laser shock peening. Journal of Alloys and Compounds, 2018, 747: 255-265.

[8] X He, L Zhao, C Deng, et al. Self-piercing riveting of similar and dissimilar metal sheets of aluminum alloy and copper alloy. Materials \& Design, 2015, 65: 923-933.

[9] B Gulenc. Investigation of interface properties and weldability of aluminum and copper plates by explosive welding method. Materials \& Design, 2008, 29(1): 275-278.

[10] Z Ni, F Ye. Dissimilar joining of aluminum to copper using ultrasonic welding. Materials and Manufacturing Processes, 2016, 31(16): 2091-2100.

[11] B S Yilbaş, A Z Şahin, N Kahraman, et al. Friction welding of StAl and AlCu materials. Journal of Materials Processing Technology, 1995, 49(3-4): 431-443.

[12] H Zhao, Z Shen, M Booth, et al. Calculation of welding tool pin width for friction stir welding of thin overlapping sheets. The International Journal of Advanced Manufacturing Technology, 2018, 98(5-8): 1721-1731.

[13] W Wang, P Han, P Peng, et al. Friction stir processing of magnesium alloys: A review. Acta Metallurgica Sinica (English Letters), 2020, 33(1): 43-57.

[14] X Liu, Y Sun, T Nagira, et al. Experimental evaluation of strain and strain rate during rapid cooling friction stir welding of pure copper. Science and Technology of Welding and Joining, 2019, 24(4): 352-359.

[15] Y Ni, L Fu, Z Shen, et al. Role of tool design on thermal cycling and mechanical properties of a high-speed micro friction stir welded 7075-T6 aluminum alloy. Journal of Manufacturing Processes, 2019, 48: 145-153.

[16] F Liu, Y Ji, Z Sun, et al. Enhancing corrosion resistance and mechanical properties of AZ31 magnesium alloy by friction stir processing with the same speed ratio. Journal of Alloys and Compounds, 2020, https://doi.org/ 10.1016/j.jallcom.2020.154452.

[17] Z Shen, Y Ding, A P Gerlich. Advances in friction stir spot welding. Critical Reviews in Solid State and Materials Sciences, 2020, 45(6): 457-534.

[18] C Schilling, J dos Santos. Method and device for joining at least two adjoining work pieces by friction welding: US, 6722556. April 20, 2004. https://patents.google.com/patent/US6722556B2/en.

[19] T Rosendo, B Parra, M Tier, et al. Mechanical and microstructural investigation of friction spot welded AA6181-T4 aluminium alloy. Materials \& Design, 2011, 32(3): 1094-1100.

[20] Z Shen, Y Ding, J Chen, et al. Microstructure, static and fatigue properties of refill friction stir spot welded 7075-T6 aluminium alloy using a modified tool. Science and Technology of Welding and Joining, 2019, 24(7): $587-600$

[21] Z Shen, W Li, Y Ding, et al. Material flow during refill friction stir spot welded dissimilar Al alloys using a grooved tool. Journal of Manufacturing Processes, 2020, 49: 260-270.

[22] P Oliveira, S Amancio-Filho, J Dos Santos, et al. Preliminary study on the feasibility of friction spot welding in PMMA. Materials Letters, 2010, 64(19): 2098-2101. 
[23] L C Campanelli, U F H Suhuddin, A Í S Antonialli, et al. Metallurgy and mechanical performance of AZ31 magnesium alloy friction spot welds. Journal of Materials Processing Technology, 2013, 213(4): 515-521.

[24] Y Chen, J Chen, B Shalchi Amirkhiz, et al. Microstructures and properties of Mg alloy/DP600 steel dissimilar refill friction stir spot welds. Science and Technology of Welding and Joining, 2015, 20(6): 494-501.

[25] U Suhuddin, V Fischer, F Kroeff, et al. Microstructure and mechanical properties of friction spot welds of dissimilar AA5754 Al and AZ31 Mg alloys. Materials Science and Engineering: A, 2014, 590: 384-389.

[26] J Shen, U F Suhuddin, M E Cardillo, et al. Eutectic structures in friction spot welding joint of aluminum alloy to copper. Applied Physics Letters, 2014, 104(19): 191901.

[27] Z Shen, Y Ding, J Chen, et al. Interfacial bonding mechanism in Al/coated steel dissimilar refill friction stir spot welds. Journal of Materials Science \& Technology, 2019, 35(6): 1027-1038.

[28] Z Shen, J Chen, Y Ding, et al. Role of interfacial reaction on the mechanical performance of Al/steel dissimilar refill friction stir spot welds. Science and Technology of Welding and Joining, 2018, 23(6): 462-477.

[29] V Firouzdor, S Kou. Al-to-Cu friction stir lap welding. Metallurgical and Materials Transactions A, 2012, 43(1): 303-315.

[30] L Zhou, R Zhang, G Li, et al. Effect of pin profile on microstructure and mechanical properties of friction stir spot welded Al-Cu dissimilar metals. Journal of Manufacturing Processes, 2018, 36: 1-9.

[31] Z Shen, Y Ding, J Chen, et al. Comparison of fatigue behavior in Mg/Mg similar and Mg/steel dissimilar refill friction stir spot welds. International Journal of Fatigue, 2016, 92: 78-86.

[32] A M Nasiri, Z Shen, J S C Hou, et al. Failure analysis of tool used in refill friction stir spot welding of Al 2099 alloy. Engineering Failure Analysis, 2018, 84: 25-33.

[33] Z Shen, X Yang, S Yang, et al. Microstructure and mechanical properties of friction spot welded 6061-T4 aluminum alloy. Materials \& Design, 2014, 54: $766-778$.

[34] M Fujimoto, S Koga, N Abe, et al. Microstructural analysis of stir zone of Al alloy produced by friction stir spot welding. Science and Technology of Welding and Joining, 2008, 13(7): 663-670.
[35] S Siddharth, T Senthilkumar, M Chandrasekar. Development of processing windows for friction stir spot welding of aluminium Al5052/copper C27200 dissimilar materials. Transactions of Nonferrous Metals Society of China, 2017, 27(6): 1273-1284

[36] A Boucherit, M N Avettand-Fènoël, R Taillard. Effect of a Zn interlayer on dissimilar FSSW of Al and Cu. Materials \& Design, 2017, 124: 87-99.

[37] M Shiraly, M Shamanian, M Toroghinejad, et al. Effect of tool rotation rate on microstructure and mechanical behavior of friction stir spot-welded Al/Cu composite. Journal of Materials Engineering and Performance, 2014, 23(2): 413-420

[38] M P Mubiayi, ET Akinlabi, M E Makhatha. Effect of process parameters on tensile strength and morphology of friction stirspot welds of aluminium and copper. 2017 8th International Conference on Mechanical and Intelligent ManufacturingTechnologies (ICMIMT), Cape Town, 2017, 48-53. https://doi.org/10.1109/ICMIMT.2017.7917433.

[39] R Heideman, C Johnson, S Kou. Metallurgical analysis of Al/Cu friction stir spot welding. Science and Technology of Welding and Joining, 2010, 15(7): 597-604.

[40] S Manickam, V Balasubramanian. Maximizing strength of friction stir spot welded bimetallic joints of AA6061 aluminum alloy and copper alloy by response surface methodology. Int. J. Mech. Eng., 2015, 3(12): 16-26.

[41] L Zhou, G Li, R Zhang, et al. Microstructure evolution and mechanical properties of friction stir spot welded dissimilar aluminum-copper joint. Journal of Alloys and Compounds, 2019, 775: 372-382.

[42] A Garg, A Bhattacharya. Strength and failure analysis of similar and dissimilar friction stir spot welds: influence of different tools and pin geometries. Materials \& Design, 2017, 127: 272-286.

[43] S Siddharth, T Senthilkumar. Study of tool penetration behavior in dissimilar Al5083/C10100 friction stir spot welds. Procedia Engineering, 2017, 173: 1439-1446.

\section{Submit your manuscript to a SpringerOpen ${ }^{\odot}$ journal and benefit from:}

- Convenient online submission

- Rigorous peer review

- Open access: articles freely available online

- High visibility within the field

Retaining the copyright to your article

Submit your next manuscript at $\boldsymbol{\nabla}$ springeropen.com 